\title{
Target Engagement of a Phosphodiesterase 2A Inhibitor Affecting Long-Term Memory in the Rat
}

\author{
Guibao Gu, Trevor Scott, Yingzhuo Yan, Noelle Warren, Adia Zhang, Ali Tabatabaei, \\ Hao Xu, Kathleen Aertgeerts, Laurent Gomez, Andrew Morse, Yu-Wen Li, \\ J. Guy Breitenbucher, Eben Massari, Jeffrey Vivian, and Anne Danks
}

Departments of Preclinical Research (G.G., T.S., N.W., A.T., A.M., Y.-W.L., J.V., A.D.), Chemistry Manufacturing and Control (A.Z.), Biology (Y.Y., E.M.), Structural Biology (H.X., K.A.), and Medicinal Chemistry (L.G., J.G.B.), Dart NeuroScience, LLC, San Diego, California

Received December 21, 2018; accepted June 24, 2019

\begin{abstract}
Inhibition of phosphodiesterase 2A (PDE2A) has been proposed as a potential approach to enhance cognitive functioning and memory through boosting intracellular cGMP/cAMP and enhancing neuroplasticity in memory-related neural circuitry. Previous preclinical studies demonstrated that PDE2A inhibitors could reverse $N$-methyl-D-aspartate receptor antagonist (5S,10R)(+)-5-methyl-10,11-dihydro-5H-dibenzo[a,d]cyclohepten-5,10imine or ketamine-induced memory deficit. Here, we report that the potent and selective PDE2A inhibitor 4-(1-azetidinyl)-7-methyl5-[1-methyl-5-[5-(trifluoromethyl)-2-pyridinyl]-1H-pyrazol-4-yl]imidazo[5,1-f][1,2,4]triazine (PF-05180999) enhances long-term memory in a contextual fear conditioning model in the rat at the oral dose of $0.3 \mathrm{mg} / \mathrm{kg}$. Target engagement at this efficacious dose was explored using in vivo autoradiography. Converse to the results of a decrease of PDE2A binding (target occupancy)
\end{abstract}

by the PDE2A inhibitor, a paradoxical increase (up to $40 \%$ ) in PDE2A binding was detected. However, a typical target occupancy curve could be generated by PF-05180999 at much higher doses. In vitro experiments using recombinant PDE2A protein or rat brain homogenate that contains native PDE2A protein demonstrated that increased cGMP after initial PDE2A inhibition could be responsible for the activation of PDE2A enzyme via allosteric binding to the GAF-B domain, leading to positive cooperativity of the dormant PDE2A enzymes. Our results suggest that when evaluating target engagement of PDE2A inhibitors for memory disorder in clinical setting with occupancy assays, the efficacious dose may not fall on the typical receptor/target curve. On the contrary, an increase in PDE2A tracer binding is likely seen. Our results also suggest that when evaluating target occupancy of enzymes, potential regulation of enzyme activities should be considered.

\section{Introduction}

Cognitive decline is one of the most frequent health complaints of healthy individuals as they age, which is even more pronounced in diagnosed neurocognitive disorders such as Alzheimer's disease, dementia with Lewy body, or frontotemporal dementia (Petersen et al., 1999; Fleischman et al., 2004; Budson and Price, 2005; American Psychiatric Association, 2013). Physiologically, long-term memory relies on the plastic enhancement of specific neural circuitry (Kandel et al., 2014; Poo et al., 2016). The neuronal plasticity requires de novo protein synthesis and the activation of cAMP response element binding protein (CREB) was found to play a pivotal role in this process (Silva et al., 1998; Tully et al., 2003; Chen et al., 2010; Kandel, 2012). CREB is a transcription factor (Brindle and Montminy, 1992). Phosphorylation of CREB promotes the expression of genes with upstream cAMP response elements (Ginty et al., 1993; Gu et al., 1996).

https://doi.org/10.1124/jpet.118.255851.
Several intracellular signaling pathways are known to activate CREB, and cAMP and $\mathrm{Ca}^{2+}$ are perhaps the most important regulators (Montminy et al., 1990; Soderling, 1999; West et al., 2001). Similarly, intracellular cGMP can also activate CREB via cGMP-dependent protein kinase (Lu and Ding, 1999; Paul et al., 2010). Therefore, it is conceivable that managing intracellular cAMP, and/or cGMP levels would help manipulate CREB phosphorylation and enhance neural circuitry plasticity (Teich et al., 2015).

The levels of intracellular cAMP and/or cGMP are regulated by phosphodiesterases (PDEs) through hydrolysis to AMP and/or GMP. A family with 11 members, each PDE subtype has multiple isoforms and splice variants (Conti and Beavo, 2007). PDE members are categorized by their catalytic domain selectivity and the properties of their regulatory domains (Schmidt, 2010; Conti and Richter, 2014). As a cGMP-stimulated cyclic nucleotide phosphodiesterase (Martins et al., 1982), phosphodiesterase 2A (PDE2A) hydrolyzes both cAMP and cGMP and possesses an allosteric GAF (cGMP-activated PDEs, adenylyl cyclase, and Fh1A)-B domain that preferentially binds cGMP (Stroop and

ABBREVIATIONS: CFC, contextual fear conditioning; CREB, CAMP response element binding protein; PDE, phosphodiesterase; PDE2A, phosphodiesterase 2A; PEG 400, polyethylene glycol 400; PF-05180999, 4-(1-azetidinyl)-7-methyl-5-[1-methyl-5-[5-(trifluoromethyl)-2-pyridinyl]1H-pyrazol-4-yl]-imidazo[5,1-f][1,2,4]triazine; PF-05270430, 4-(3-fluoroazetidin-1-yl)-7-methyl-5-(1-methyl-5-(4-(trifluoromethyl)phenyl)-1H-pyrazol-4-yl)imidazo[1,5-f][1,2,4]triazine. 
Beavo, 1991; Martinez et al., 2002; Wu et al., 2004; Pandit et al., 2009). Via a positive cooperativity mechanism, cGMP binding to the GAF domain causes a conformational change in the linker region between the catalytic and regulatory domains of the enzyme, swings the H-loops out, opens the access of the substrate, and thereby upregulates the hydrolytic activity of PDE2A (Pandit et al., 2009).

The high abundance and preferential expression in the brain indicates that PDE2A could serve as a suitable target for pharmacological intervention in memory disorders. PDE2A is highly expressed in brain regions that are important for cognitive functions, including the cerebral cortex, hippocampus, and striatum (Stephenson et al., 2012; Kelly et al., 2014). In in vitro and in vivo animal studies, PDE2A-selective inhibitors enhanced long-term potentiation and improved the performance of multiple memory tasks (Boess et al., 2004; Domek-Łopacińska and Strosznajder, 2008; Helal et al., 2018; Nakashima et al., 2018).

Critical to the advancement of PDE2A inhibitor drugs in clinic is the identification and validation of specific biomarkers of drug action in the central nervous system. Recently, 4-(3fluoroazetidin-1-yl)-7-methyl-5-(1-methyl-5-(4-(trifluoromethyl) phenyl)-1 $H$-pyrazol-4-yl)imidazo[1,5-f][1,2,4]triazine (PF-05270430) (Chen et al., 2016) was reported to be a useful positron emission tomography ligand. The utility of PDE2A positron emission tomography ligands depends on the establishment of a defined occupancy/efficacy relationship with the desired pharmacological effect. The PDE2A inhibitor $N-((1 S)-$ 1-(3-fluoro-4-(trifluoromethoxy)phenyl)-2-methoxyethyl)7-methoxy-2-oxo-2,3-dihydropyrido[2,3-b]pyrazine-4(1H)carboxamide reversed (5S,10R)-(+)-5-methyl-10,11-dihydro-5H-dibenzo[ $a, d]$ cyclohepten-5,10-imine-induced episodic memory deficits at oral doses of 3 and $10 \mathrm{mg} / \mathrm{kg}$ (but not $1 \mathrm{mg} / \mathrm{kg}$ ), which corresponded well with the dose that elevated hippocampal cGMP levels, where occupancy was reported to be about $46 \%$ and $63 \%$ at these doses, respectively (Mikami et al., 2017a). However, $N$-((1S)-1-(3fluoro-4-(trifluoromethoxy)phenyl)-2-methoxyethyl)-7methoxy-2-oxo-2,3-dihydropyrido[2,3-b]pyrazine-4(1H)-carboxamide significantly enhanced performance in the rat novel object recognition study (Mikami et al., 2017b) at a dose of $0.1 \mathrm{mg} / \mathrm{kg}$, presumably at occupancy far lower than $46 \%$. Similarly, another PDE2A inhibitor, 4-(1-azetidinyl)-7-methyl-5-[1-methyl-5-[5-(trifluoromethyl)-2-pyridinyl]-1 $H$-pyrazol-4-yl]-imidazo[5,1-f][1,2,4] triazine (PF-05180999), demonstrated reversal of ketamineinduced working memory deficits in rats at doses of $0.1-$ $0.32 \mathrm{mg} / \mathrm{kg}$, s.c., corresponding to "several fold less than $50 \%$ occupancy" (Helal et al., 2018). The phenomenon of efficacy in rodent memory models at very low occupancy was a common observation in our PDE2A drug discovery efforts (unpublished data).

In evaluating PDE2A target occupancy by PDE2A inhibitors, the positive cooperativity of the enzyme should be considered. Since the doses of the PDE2A inhibitor required to reverse chemical-challenged cognitive deficits were relatively high (Mikami et al., 2017a; Helal et al., 2018), this positive cooperativity might have been masked. In the current study, we used a nonchemically challenged long-term memory retention model and in vivo autoradiography to investigate the target engagement of a potent and selective PDE2A inhibitor, PF-05180999, at the low efficacious doses.

\section{Materials and Methods}

\section{Materials}

The NIR Video Fear Conditioning System Contextual Package was used (Med Associates, Inc., Vermont). Male CD rats (350-450 g) were obtained from Charles River (Hollister, CA). Rat whole brain membranes $(0.6 \mathrm{mg} / \mathrm{ml})$ were used and ${ }^{3} \mathrm{H}-\mathrm{PF}-05270430$ was obtained from Moravek (Brea, CA). Costar 96-well V-bottom dilution plates, Greiner 96-well masterblock ( $0.5 \mathrm{ml}) \mathrm{V}$-bottom assay plates, and Perkin Elmer 96-well unifilter-GF/C filter plates (Boston, MA) were employed. MicroScint-20 (Perkin Elmer), Brandel Harvester (model MWXRI96TI), 2450 Micro Plate Reader (Perkin Elmer), Omni Prep Multi Sample Homogenizer (Kennesaw, GA), a cryostat (CM-1950; Leica Microsystems), and a liquid scintillation counter (model LS6500; Beckman Coulter, Inc.) were also used. Jugular vein-cannulated male CD rats (75-100 g) were obtained from Charles River. A Plexiglass rat restrainer (Braintree Scientific, Inc.) and a $\beta$-imager (Biospace Laboratory, Paris, France) were used.

\section{Methods}

Animals. The protocols performed in the present rodent studies were approved by the Institutional Animal Use and Care Committee of Dart NeuroScience, LLC, in accordance with the guidelines of the National Institutes of Health and the US Department of Agriculture for the care and use of laboratory animals. Male CD rats, naive or jugular vein-cannulated, weighing from 100 to $450 \mathrm{~g}$, were obtained from Charles River Laboratories and housed in cages on a 12 hours light/dark cycle. Food and water were available ad libitum.

Drugs. The drugs used included PF-05180999, PDE2A $\left(\mathrm{IC}_{50}=1.6\right.$ $\mathrm{nM},>56,250$-fold selectivity of PDE2A over PDE1B1, PDE3A1, PDE4D3, and PDE5A1), and bovine PDE6 (26,969-fold over PDE7B; $>56,250$-fold over PDE8B and PDE9A1; 2030-fold over PDE10A; and 50,090-fold over PDE11A4) (Helal et al., 2018) made by Dart NeuroScience, LLC (San Diego, CA), as well as ${ }^{3} \mathrm{H}-\mathrm{PF}-05270430$, PDE2A $\left(\mathrm{IC}_{50}=0.53 \mathrm{nM},>56,604\right.$-fold selectivity for PDE2A over PDE1B, >56,604-fold over PDE3A and PDE4D, 49,057-fold over PDE5A, >18,868-fold over PDE6A, 22,642-fold over PDE7B, $>18,868$-fold over PDE8B and PDE9A, 7358-fold over PDE10A, and $>18,868$-fold over PDE11) (Zhang, 2013), made by Dart NeuroScience, LLC, and Moravek Biochemicals. PF-05180999 was freshly prepared in 10:40:50 or 10:60:30 N-methyl-2-pyrrolidone:polyethylene glycol 400 (PEG 400): $\mathrm{H}_{2} \mathrm{O}$ solution. ${ }^{3} \mathrm{H}-\mathrm{PF}-05270430$ was freshly prepared in a solution of 50:30:20 PEG 400: $\mathrm{H}_{2} \mathrm{O}$ :ethanol.

Contextual Fear Conditioning Task. The contextual fear conditioning (CFC) task was performed in a conditioning chamber placed in a sound-attenuating box (Med Associates Inc.) during the light phase of the cycle. CD male rats, weighing from 350 to $450 \mathrm{~g}$, were doubly housed in the holding room for 2 weeks prior to training/test. One hour after receiving an oral dose of vehicle (10:40:50; $N$-methyl-2pyrrolidone:PEG 400: $\mathrm{H}_{2} \mathrm{O}$ ) or PF-05180999 (synthesized by the Department of Chemistry, Dart Neuroscience, LLC) at doses ranging from 0.03 to $1 \mathrm{mg} / \mathrm{kg}(2 \mathrm{ml} / \mathrm{kg})$, all rats were trained and tested in the conditioning chambers equipped with a stainless-steel grid floor through which footshocks were delivered. Training consisted of placing the rats in the chamber, and after a 120 -second baseline two electrical footshocks (2-second duration; $0.4 \mathrm{~mA}$ ) were delivered separated by a 60 -second intertrial interval. The two shocks serve as the aversive unconditioned stimulus to induce a weak memory. Thirty seconds after the final shock, rats were removed from the chamber and returned to the home cage. Long-term memory was assessed 24 hours after training by placing the rats into the chambers with the same training context and calculating the percentage of time spent freezing during 3 minutes without footshock. Freezing behavior was defined as the complete lack of movement, except for respiration, and was measured automatically using Video Freeze software.

Radioactive Tracer Labeling. PF-05270430 was labeled with tritium as the PDE2A ligand by Moravek Biochemicals. The ligand 
was radiolabeled from the cold compound synthesized by the Department of Chemistry, Dart Neuroscience, LLC, by a direct exchange of hydrogen atoms with its isotope tritium using Crabtree's catalyst and tritium gas under anhydrous conditions. The reaction was stirred at room temperature for 24 hours. The crude product was dissolved in ethanol and evaporated to dryness three times. The radioligand was purified on a HPLC-C18 Capcell Pak column (mobile phase: $45 \%$ acetonitrile and $0.1 \%$ trifluoroacetic acid; UV: $254 \mathrm{~nm}$; flow rate: $6 \mathrm{ml} / \mathrm{min}$ ). A radiochemical purity of over $99.3 \%$ and specific activity of over $87 \mathrm{Ci} / \mathrm{mmol}$ were achieved. The tritium tracer was then packaged in $100 \%$ ethanol and stored at $-20^{\circ} \mathrm{C}$ before use.

Rat Brain Membrane Preparation. Naive rats were deeply anesthetized with isoflurane vapor in a Bell jar and brains quickly removed from the skull and immediately frozen in isopentane bath chilled with dry ice. Frozen brains were then stored in a freezer at $-80^{\circ} \mathrm{C}$ before use. During membrane preparation, whole flashfrozen rat brains were thawed on ice and split into two halves down the midline. Each half was added to a $15-\mathrm{ml}$ centrifugation tube containing $7 \mathrm{ml}$ of ice-cold assay buffer [ $50 \mathrm{mM}$ Tris HCL, $1 \mathrm{mM} \mathrm{MgCl} 2,1 \mathrm{mM}$ $\mathrm{CaCl}_{2}$, and $2 \mathrm{mM} \mathrm{KCl} \mathrm{(pH} \mathrm{7.4)].} \mathrm{Brains} \mathrm{were} \mathrm{further} \mathrm{homogenized} \mathrm{on}$ ice using the Omni Prep Multi Sample Homogenizer at 14,000 rpm for 90 seconds. After homogenization, samples were centrifuged at $15,000 \mathrm{~g}$ for 30 minutes. The supernatant was discarded and the pellet was resuspended in $7 \mathrm{ml}$ of ice-cold assay buffer. Resuspended membranes were then pooled together and kept on ice. Following the determination of the total protein concentration using the bicinchoninic acid method, $1 \mathrm{ml}$ aliquots were made, frozen on dry ice, and stored at $-80^{\circ} \mathrm{C}$ before use.

$\boldsymbol{K}_{\mathbf{d}}$ and $\boldsymbol{B}_{\max }$ Determination. The dissociation constant at equilibrium $K_{\mathrm{d}}$ and maximum number of binding sites $B_{\max }$ values of the radiolabeled tracer were measured with rat brain homogenate. Binding reactions were set up in a 96 -well assay plate $(156 \mu \mathrm{g} / \mathrm{well}$ total protein). Various concentrations of ${ }^{3} \mathrm{H}$-radioligand in the absence (for total binding) or presence (for nonspecific binding) of $10 \mu \mathrm{M}$ unlabeled form of the ligand were incubated with rat brain homogenate protein at room temperature for 2 hours. The assay solutions were then filtered using a Brandel Harvester onto a 96 -well GF/C filter plate. The filter plate was washed using 21 of wash buffer [ $50 \mathrm{mM}$ Tris $\mathrm{HCL}$ and $1 \mathrm{mM} \mathrm{MgCl}{ }_{2}(\mathrm{pH}$ 7.4)]. After drying, each well of the filter was added to $50 \mathrm{ml}$ of Microscint-20 scintillation fluid and the plate was counted with a MicroBeta counter (Perkin Elmer). The specific binding was calculated by subtracting the nonspecific binding from the total binding for each concentration used in the assay and the data were fit to a one-site-specific binding curve using GraphPad Prism software (GraphPad, Inc., San Diego, CA). The $B_{\max }$ value was calculated using GraphPad Quick Calcs based on the specific activity of the radioligand, microbeta counter efficiency (43\%), and total protein concentration (156 $\mu \mathrm{g} / \mathrm{well})$.

$\boldsymbol{K}_{\mathbf{i}}$ Assay. An in vitro $K_{\mathrm{i}}$ assay was performed to examine displacement of the radiolabeled PDE2A tracer by PF-05180999. Compound PF-05180999 was first serially diluted, ranging from 0.05 $\mathrm{nM}$ to $50 \mu \mathrm{M}$ in duplicate with $0.5 \%$ DMSO/assay buffer in a 96 -well $0.5 \mathrm{ml} \mathrm{V}$-bottom assay plate; total binding or nonspecific binding controls were placed in the wells by skipping the test article or adding $10 \mu \mathrm{M}$ of the unlabeled form of the radioligand in the $0.5 \% \mathrm{DMSO} /$ assay buffer. ${ }^{3} \mathrm{H}-\mathrm{PF}-05270430$ at the concentration of $K_{\mathrm{d}}$ and $156 \mu \mathrm{g} /$ well total protein of the membrane prep was added into each well and incubate for 2 hours at room temperature with slow agitation. The assay solutions were harvested and the counts were measured following the procedures described previously. The specific binding was calculated by subtracting the nonspecific binding from the total binding for each concentration used in the assay. The $\mathrm{IC}_{50}$ value was determined and the 11-point inhibition curve was plotted using GraphPad Prism software. The $\mathrm{IC}_{50}$ values were converted to $K_{\mathrm{i}}$ values according to the Chang-Prusoff equation: $K_{\mathrm{i}}=\mathrm{IC}_{50} /\left(1+[S] / K_{\mathrm{d}}\right)$, where $[S]=K_{\mathrm{d}}$.

In Vivo PDE2A Occupancy. An in vivo autoradiography method was used to explore PDE2A target occupancy in the rat by
$\mathrm{PF}-05180999$. The radioactive tracer ${ }^{3} \mathrm{H}-\mathrm{PF}-05270430$ was first characterized in live animals by intravenous dosing into jugular vein-cannulated CD rats weighing from 100 to $150 \mathrm{~g}$ to identify the proper dose and time point at which the radioactivity of the region of interest for the tracer reached $0.5-1.0 \mathrm{cpm} / \mathrm{mm}^{2}$ and the best signal-tonoise ratio (region of interest/reference region) was achieved. In the in vivo occupancy experiments, $0.03-150 \mathrm{mg} / \mathrm{kg}$ PF-05180999 or vehicle (10:40:50 or 10:60:30 N-methyl-2-pyrrolidone:PEG 400: $\mathrm{H}_{2} \mathrm{O}$ ) was orally dosed. Fifty minutes later, approximately $300 \mu \mathrm{l}$ blood was drawn from the jugular cannula and collected in tubes with a lithium heparin gel barrier (Terumo Corporation, Somerset, NJ). Plasma was prepared by centrifugation for compound concentration analysis. Immediately following plasma collection, rats then received a total volume of $600 \mu \mathrm{l}$ tritiated tracer $(0.5 \mu \mathrm{Ci} / \mathrm{g}$ or $1 \mu \mathrm{Ci} / \mathrm{g}$ per body weight, in 50\% PEG 400, $20 \%$ ethanol, and $30 \% \mathrm{H}_{2} \mathrm{O}$ vehicle) into the jugular vein, followed by $500 \mu \mathrm{l}$ saline flush. Injections lasted at least for 30 seconds to avoid circulatory failure. Ten minutes later, following anesthesia with isoflurane in a Bell jar, each rat was decapitated, $500 \mu \mathrm{l}$ of trunk blood was collected in tubes with lithium heparin gel barrier, and plasma was isolated by centrifugation for radioactivity quantitation. Brain tissue from each rat was quickly removed, frozen in dry ice-chilled isopentane, and stored at $-80^{\circ} \mathrm{C}$ before further processing. Sagittal brain sections were cut at $20 \mu \mathrm{m}$ with a Leica CM1950 cryostat and mounted on Superfrost Plus slides. After drying at room temperature, slides were imaged with a Beta-Imager (Biospace Laboratory). The acquired images were then analyzed with M3Vison software. The occupancy values were calculated as follows: $\%$ occupancy $=($ vehicle binding - drug binding $) /$ vehicle binding $\times$ 100 . The nondisplaceable signals in the reference region, referred to as the nonspecific binding, were subtracted from all values prior to the calculation. Negative values were excluded in occupancy-exposure curve plotting.

In Vitro Recombinant PDE2A Protein Binding. To elucidate the role of cGMP activation produced by PDE2A inhibition, an in vitro binding assay was developed using a recombinant PDE2A protein. The cDNA corresponding to residues 215-900 of human PDE2A3 (UniProt entry: O00408), followed by a tobacco etch virus protease cleavage site, a $10 \mathrm{X}$ polyhistidine tag, and a FLAG tag, was synthesized, codon optimized (DNA2.0; Neward, CA), and subcloned into a modified pFastbac1 vector (Thermo Fisher Scientific, Waltham, MA). High titer recombinant baculoviruses ( $>10^{8}$ infective viral particles per milliliter) were generated using the Bac-to-Bac Baculovirus Expression System (Thermo Fisher Scientific) and used to infect Spodoptera frugiperda 9 insect cells at a density of $2 \times 10^{6}$ cells $/ \mathrm{ml}$ with high titer viral stock at a multiplicity of infection of 5 . Infected cells were grown at $27^{\circ} \mathrm{C}$ for $48-96$ hours prior to being harvested, and the cell pellets were stored at $-80^{\circ} \mathrm{C}$. Then, $2.5 \mathrm{l}$ of frozen cells was broken into small pieces and resuspended into $200 \mathrm{ml}$ lysis buffer [50 mM Tris ( $\mathrm{pH} 7.5), 800 \mathrm{mM} \mathrm{NaCl}, 5 \%$ glycerol, $0.25 \mathrm{mM}$ tris(2carboxyethyl)phosphine, and one tablet of a protease inhibitor cocktail (Roche)]. After centrifugation, the sample was passed through a cheese cloth. Twenty microliters of Universal Nuclease (Thermo Fisher Scientific) and $9 \mathrm{ml}$ of a Probond Ni Resin (Thermo Fisher Scientific) were added to the sample and incubated for 3 hours. Gravity-assisted flow was used to wash the resin with $300 \mathrm{ml}$ of $50 \mathrm{mM}$ Tris (pH 7.5), $600 \mathrm{mM} \mathrm{NaCl}, 5 \%$ glycerol, and $20 \mathrm{mM}$ imidazole. The protein was then eluted with seven column volumes $(\sim 25 \mathrm{ml})$ of $50 \mathrm{mM}$ Tris $(\mathrm{pH}$ 7.5), $600 \mathrm{mM} \mathrm{NaCl}, 5 \%$ glycerol, and $300 \mathrm{mM}$ imidazole. The protein was then further purified by size-exclusion chromatography using a Superdex 200 column (GE Healthcare Life Sciences) with a flow of $1 \mathrm{ml} / \mathrm{min}$ using a buffer containing $25 \mathrm{mM}$ Hepes (pH 7.5), $50 \mathrm{mM}$ $\mathrm{NaCl}$, and $0.25 \mathrm{mM}$ tris(2-carboxyethyl)phosphine. The fractions with the desired retention time were pooled. The final protein concentration was $0.56 \mathrm{mg} / \mathrm{ml}$.

cGMP Regulation of PDE2A Ligand Binding. PDE2A (215-900) protein (1 nM) was incubated with $10 \mathrm{nM}{ }^{3} \mathrm{H}-\mathrm{PF}$ 05270430 and various concentrations of cGMP $(0-100 \mathrm{mM})$ in assay buffer [25 mM Tris $\mathrm{HCl}$ ( $\mathrm{pH} 7.4$ ), $5 \mathrm{mM} \mathrm{MgCl}_{2}, 0.2 \%$ bovine serum 
albumin, $0.5 \mathrm{mM}$ 1,4-dithiothreitol, and $0.05 \%$ Tween-20] at room temperature for 1 hour in 96 -well nonbinding surface plates (Corning). PDE2A was subsequently captured by addition of a 1:4 dilution of ANTI-FLAG M2 Affinity Gel (Sigma) prepared in assay buffer, incubated for an additional 1 hour at room temperature, and then transferred to glass fiber filter plates (UniFilter-96 GF/C Microplate; Perkin Elmer Life Sciences) that were presoaked in $0.5 \%$ polyethyleneimine solution. Filters were washed six times with wash buffer [50 mM Tris ( $\mathrm{pH} 7.5$ ), $5 \mathrm{mM} \mathrm{MgCl}$, and $1 \mathrm{mM}$ EDTA] using the Brandel Harvester and the remaining radioactivity was quantified using a Microbeta Trilux counter (Perkin Elmer Life Sciences) using Microscint-20 (PerkinElmer Life Sciences). Nonspecific binding was determined in the presence of $10 \mu \mathrm{M}$ PF-05270430 and $100 \mu \mathrm{M}$ cGMP.

$K_{d}$ and $B_{\max }$ Determination in the Presence or Absence of cGMP. In a 96-well nonbinding surface plate, $1 \mathrm{nM}$ of PDE2A (215-900) protein and various concentrations of ${ }^{3} \mathrm{H}-\mathrm{PF}-05270430$ $(0-200 \mathrm{nM})$ were incubated in assay buffer $[25 \mathrm{mM}$ Tris $\mathrm{HCl}(\mathrm{pH}$ 7.4), $5 \mathrm{mM} \mathrm{MgCl} 2,0.2 \%$ bovine serum albumin, $0.5 \mathrm{mM}$ 1,4-dithiothreitol, and $0.05 \%$ Tween-20] or assay buffer containing $30 \mu \mathrm{M}$ cGMP at room temperature for 1 hour. PDE2A protein capture, washing, and counting of the remaining radioactivity were performed as described previously. The $K_{\mathrm{d}}$ and $B_{\max }$ values were determined in GraphPad Prism 7 by fitting the data using a one-site model.

In Vitro Native PDE2A Protein Binding in the Absence or Presence of cGMP. In vitro PDE2A binding in the absence or presence of cGMP was examined with native PDE2A protein in rat brain homogenate, as prepared peviously. Then, $0.1 \mathrm{mg} / \mathrm{ml}$ protein was incubated with $0.5 \mathrm{nM}{ }^{3} \mathrm{H}-\mathrm{PF}-05270430$ and various concentrations of cGMP $(0-10 \mathrm{mM})$ in assay buffer [50 mM Tris $\mathrm{HCl}, 1 \mathrm{mM}$ $\mathrm{MgCl}_{2}, 1 \mathrm{mM} \mathrm{CaCl}_{2}$, and $2 \mathrm{mM} \mathrm{KCl} \mathrm{(pH} \mathrm{7.4)]} \mathrm{at} \mathrm{room} \mathrm{temperature} \mathrm{for}$ 5 minutes in 96-well nonbinding surface plates (Corning) in the presence of $10 \mu \mathrm{M}$ PDE10 inhibitor 2-(4-(1-methyl-4-pyridin-4-yl1H-pyrazol-3-yl)phenoxymethyl)quinoline and a PDE1 inhibitor . Nonspecific binding was determined in the presence of $10 \mu \mathrm{M}$ PF05270430 and $100 \mu \mathrm{M}$ cGMP. The assay solutions were then filtered using the Brandel Harvester onto a 96-well GF/C filter plate. After washing and drying the filter plate, $50 \mathrm{ml}$ of Microscint- 20 scintillation fluid was added to each well of the filter and the plate was counted with a MicroBeta counter (PerkinElmer Life Sciences).

Statistical Analysis. Data acquired were analyzed using GraphPad Prism 7.0. All data are presented as mean with S.E.M. The statistical significance was calculated using one-way ANOVA with Bonferroni's post hoc test. A $P$ value of less than 0.05 is defined as significant. Graphs were plotted using Prism software.

\section{Results}

Characterization of $K_{d}$ and $B_{\max }$ Values of ${ }^{3} \mathrm{H}$ PF-05270430 with Rat Brain Homogenate and Brain Sections, Binding of PDE2A. PF-05270430 was reported to be highly selective and potent. In a cGMP-stimulated human recombinant full-length PDE2A enzymatic activity assay, its $\mathrm{IC}_{50}$ value was $0.53 \mathrm{nM}$ (Zhang et al., 2013). Based on its favorable profile of brain penetration, efflux, and plasma/brain free fraction, the compound was advanced, labeled with ${ }^{18} \mathrm{~F}$, and successfully used in positron emission tomography imaging studies in cynomolgus monkeys and humans (Zhang et al., 2013; Chen et al., 2016; Naganawa et al., 2016). In the current study, after tritiation, ${ }^{3} \mathrm{H}-\mathrm{PF}$ 05270430 maintained its high potency and selectivity. The tracer yielded over $95 \%$ specific binding with rat brain homogenate, with a $K_{\mathrm{d}}$ value of $9.4 \mathrm{nM}$, a 10 - to 20 -fold shift compared with the in vitro functional enzymatic activity assay commonly seen in other PDEs as well due to differences in the readout and the enzyme proteins used. The $B_{\max }$ value was $1515 \mathrm{fmol} / \mathrm{mg}$ (Fig. 1A). Incubation of the tracer (10 $\mathrm{nM}$ for 1 hour at room temperature) with rat brain sections demonstrated a distinctive PDE2A binding pattern (Fig. 1B), consistent with the pattern of PDE2A expression in the brain (Stephenson et al., 2012; Kelly et al., 2014). In the rat brain, high density of the PDE2A binding signals was observed in the olfactory bulb, olfactory tubercle, cortex, hippocampus, striatum, ventral tegmental area, as well as the substantia nigra. On coronal sections (data not shown), in the striatum, higher density of binding signals was found in the globus pallidus than in the caudate putamen.

Establishing an Exposure-Occupancy Relationship for PF-05180999 at the Higher Dose Range. After characterization of the radioligand we established an occupancy dose response for PF-05180999 between the doses of 1 and $150 \mathrm{mg} / \mathrm{kg}$. A dose-dependent curve was generated against the total plasma concentration of the compound (Fig. 2A), with a slope of around 1 and $\mathrm{IC}_{50}$ (50\% occupancy) of $965.8 \mathrm{nM}$ total plasma concentration of the compound. The $50 \%$ occupancy value, when backcalculated based on the compound's brain penetration, free plasma, and free brain percentage, was 122.7 $\mathrm{nM}$, which is largely consistent with the in vitro $K_{\mathrm{i}}$ assay value $(49.0 \mathrm{nM})$ using rat brain homogenate (Fig. 2B). The plasma radioactivity levels at the time when brains were harvested looked constant; no dose-dependent increase or decrease was observed (Fig. 2C). However, because each treatment group only had two rats, statistical analysis was not possible.

Efficacy of PF-05180999 in the CFC Rat Model. To characterize the efficacy of PF-05180999, we choose to perform a model of long-term memory that did not involve the use of chemical impairment. In this case, the 24-hour conditioned fear test was used. Pretreatment with an oral dose of PF05180999 at the dose of $0.3 \mathrm{mg} / \mathrm{kg}$ prior to training, which consisted of $20.4 \mathrm{~mA}$ unconditioned footshocks in the training context, produced a significant increase in the rate of freezing behavior 24 hours later compared with vehicle-dosed animals. Doses at 0.03 or $1 \mathrm{mg} / \mathrm{kg}$ were not efficacious, suggesting an inverted U-shaped dose effect (Fig. 3). Interestingly, this dose corresponded well to the previously reported reversal of ketamine working memory impairment reported by Pfizer (Helal et al., 2018).

In Vivo PDE2A Binding following the Lower Dose Range of PF-05180999. In vivo autoradiography was performed to investigate target engagement by PF-05180999 at the efficacious dose range in the CFC behavior assay. Interestingly, instead of displacing and thereby decreasing PDE2A tracer binding, lower doses of PF-05180999 appeared to increase the tracer binding, and this increased binding tended to return to baseline beyond $3 \mathrm{mg} / \mathrm{kg}$ (Fig. 4, A and B). The increased PDE2A binding does not appear to be the result of increased brain entry of the radioactive tracer since the plasma radioactivity levels remained constant at the time when the brain samples were harvested (Fig. 4C). Total plasma concentration of the drug ranged from 10 to $100 \mathrm{nM}$ (Table 1). Since there were only two to four rats per group in the first occupancy study and the increase in PDE2A values appeared to be variable, which made one-way ANOVA analysis treacherous, a separate study with increased $n$ number per group was performed. PF-05180999 at the oral dose of $0.3 \mathrm{mg} / \mathrm{kg}$ significantly increased PDE2A tracer binding in vivo compared with the vehicle-control group (Fig. 5), confirming the results in the previous observation. 
A

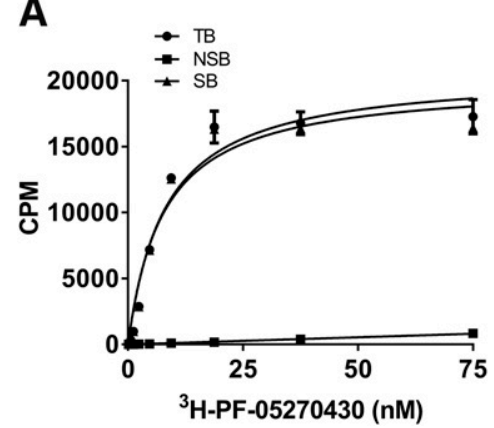

B

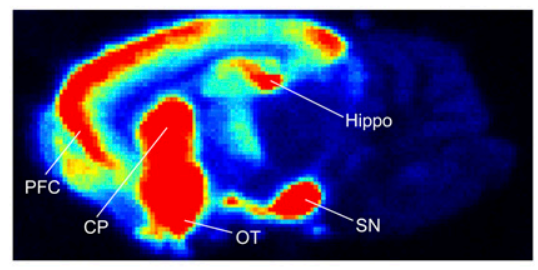

Fig. 1. Characterization of PDE2A radiolabeled tracer $\left[{ }^{3} \mathrm{H}\right]$ PF-05270430 with rat (A) brain homogenate, and the distribution of PDE2A binding with $\left[{ }^{3} \mathrm{H}\right] \mathrm{PF}-05270430$ on sagittal rat (C) brain sections. Specific binding exceeded over $95 \%$ in the rat (A and $\mathrm{B})$, and distinctive binding signals (red, yellow, and green) were observed in the rat brain sections $(\mathrm{C}$ and $\mathrm{D})$. $\mathrm{CP}$, caudate putamen; CPM, counts per minute; Hippo, hippocampus; NSB, non-specific binding; OT, olfactory tubercle; PFC, prefrontal cortex; SB, specific binding; SN, substantia nigra; TB, total binding.
The dose response was repeated in the other two separate experiments. The pattern of the PDE2A binding following lower doses of PF-05180999 was established after combining the data from all four experiments (Fig. 6).

In Vitro PDE2A Ligand Binding in the Absence or Presence of cGMP. The increased local cGMP levels produced by the lower doses of PDE2A inhibitors were suspected to cause the increase in PDE2A tracer binding. To test this hypothesis, in vitro PDE2A binding in the presence or absence of various concentrations of cGMP was examined using near full-length or catalytic-domain recombinant $\mathrm{PDE} 2 \mathrm{~A}$ protein or natural PDE2A enzyme in rat brain homogenate. cGMP dosedependently increased PDE2A tracer binding to the near fulllength PDE2A recombinant enzyme protein (the activation phase). This facilitation plateaued when cGMP reached 10-100 $\mu \mathrm{M}$. However, when the cGMP concentration continued to rise above $100 \mu \mathrm{M}$, PDE2A binding decreased in a dosedependent pattern (the inhibition phase) (Fig. 7). With the catalytic domain alone, such a dual cGMP effect disappeared; only the inhibition phase was present (data not shown). Similarly, cGMP also showed a dual-phase effect with the natural PDE2A protein in the rat brain homogenate in the presence of $10 \mu \mathrm{M}$ PDE1 and PDE10 inhibitors. The activation effect plateaued at the concentration of $3-16 \mu \mathrm{M}$ before the inhibition phase kicked in (Fig. 8). The cGMP-induced activation of PDE2A binding appeared to be due to the increase in PDE2A affinity. In the presence of the fixed concentration of $30 \mu \mathrm{M}$ cGMP, the PDE2A binding curve shifts to the left. Compared with the control, the $K_{\mathrm{d}}$ value decreased from 17.2 to $2.4 \mathrm{nM}$, an increase of 7.2-fold in affinity (Fig. 9).

\section{Discussion}

The current study demonstrated that the potent and selective PDE2A inhibitor PF-05180999 enhances long-term memory in a contextual fear conditioning model in the rat at the oral dose of $0.3 \mathrm{mg} / \mathrm{kg}$. However, the target engagement study using in vivo autoradiography failed to show a decrease
A

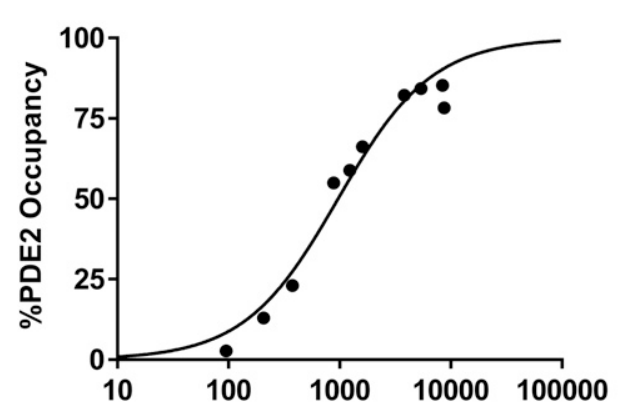

Total Plasma [PF05180999] (nM)

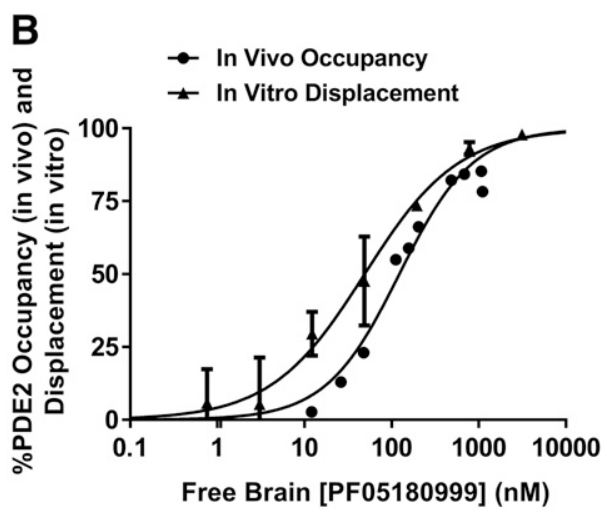

Free Brain [PF05180999] (nM)
Fig. 2. (A) PDE2A occupancy following the higher oral dose range (1-150 $\mathrm{mg} / \mathrm{kg})$ of $\mathrm{PF}$ 05180999, plotted against the total plasma concentration of the drug. (B) PDE2A target occupancy plotted against the calculated free brain concentration (solid circles) is consistent with the result of the in vitro displacement $\left(K_{\mathrm{i}}\right)$ assay (solid triangles). (C) PF-05180999 did not appear to impact radioactivity levels in plasma 10 minutes after $1 \mu \mathrm{Ci} / \mathrm{g}$ injection of the tracer when the brain samples were harvest since a dose-dependent increase or decrease by the compound could not be established $(n=$ 2). DPM, disintegrations per minute. 


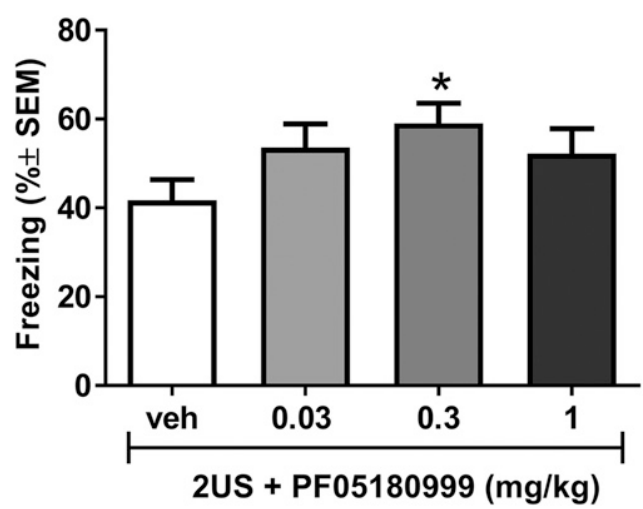

Fig. 3. PF-05180999 enhances long-term memory in the CFC model in the rat. Mean percentage of freezing $( \pm$ S.E.M. $)$ during the 3-minute contextual fear memory test. PF-05180999 dosed at $0.3 \mathrm{mg} / \mathrm{kg}$ enhanced long-term contextual fear memory compared with the vehicle-treated two unconditioned stimulus (2US) control rats. Rats ( $n=32 /$ group) were dosed [by mouth, $2 \mathrm{ml} / \mathrm{kg}$, vehicle = 10:40:50 ( $N$-methyl-2-pyrrolidone:PEG 400: $\mathrm{H}_{2} \mathrm{O}$ or PF05180999)] 60 minutes prior to training (which consisted of 20.4 $\mathrm{mA}$ footshocks in the training context). Contextual fear memory was tested 24 hours after training. Asterisk $=P<0.05$ vs. 2US vehicle (ANOVA, least-mean-square post hoc comparison).

in PDE2A binding (target occupancy) at this efficacious dose. Instead, a paradoxical, up to $40 \%$ increase in PDE2A binding was detected. At higher doses, this compound did decrease PDE2A binding and an occupancy curve against plasma concentration could be generated.

A similar occupancy curve by PF-05180999 has been reported by Chen et al. (2016) in the cynomolgus monkey. Using the same PF-05270430 compound as the tracer $\left({ }^{18} \mathrm{~F}\right.$-labeled $)$, the authors reported a half-maximal effective plasma concentration of $69.4 \mathrm{ng} / \mathrm{ml}$ in the region of the striatum (equivalent to $167.5 \mathrm{~nm}$ ), several fold more potent than what we saw in the rat. This potency mismatch may stem from the differences of species and/or methods used in the experiment and data analysis.

The efficacious dose of the compound in the rat CFC model in the present study overlaps with the dose causing the
TABLE 1

Plasma drug concentration following low oral doses of PF-05180999

\begin{tabular}{|c|c|}
\hline PF-05180999 (by Mouth) & Total Plasma \\
\hline$m g / k g$ & $n M$ \\
\hline 0.03 & BQL \\
\hline 0.3 & 14.2 \\
\hline 1 & 38.2 \\
\hline 3 & 110.0 \\
\hline
\end{tabular}

BQL, below the quantification limit.

increase of PDE2A binding capacity. However, it should not assume that the memory enhancement effect by PF-05180999 is due to the activation of PDE2A rather than inhibition of the enzyme. Since the PF-05180999 compound itself does not directly activate PDE2A, as it failed to increase the binding of the recombinant enzyme in the absence of cGMP at various concentrations (Y. Yan, unpublished data), the increased PDE2A binding capacity appears to be due to the increased level of cGMP (the product of phosphodiesterase 2 enzyme inhibition). Our in vitro studies confirmed that cGMP does cause the allosteric modulation of the enzyme itself, as demonstrated by the increase in the tracer binding in both recombinant and natural PDE2A proteins. Increased cGMP at the appropriate levels also activates its downstream kinases and the intracellular cascade and enhances long-term memory in the rat CFC model.

Receptor/target occupancy has been widely used as a platform to explore target engagement for targets such as G-protein-coupled receptors (Kapur et al., 1995; Hargreaves, 2002; Yokoi et al., 2002; Raddad et al., 2016) and transporters (Martin-Facklam et al., 2013; Finnema et al., 2015) in drug discovery and development. Efforts have been made to demonstrate target occupancy for enzymes (Freedman et al., 2005; Delnomdedieu et al., 2017) as well. For some enzymes, one problem for occupancy studies is the cooperativity of the endogenous substrate with the enzyme itself when the compound investigated is the enzyme inhibitor. This cooperativity can change the affinity of the enzyme and significantly
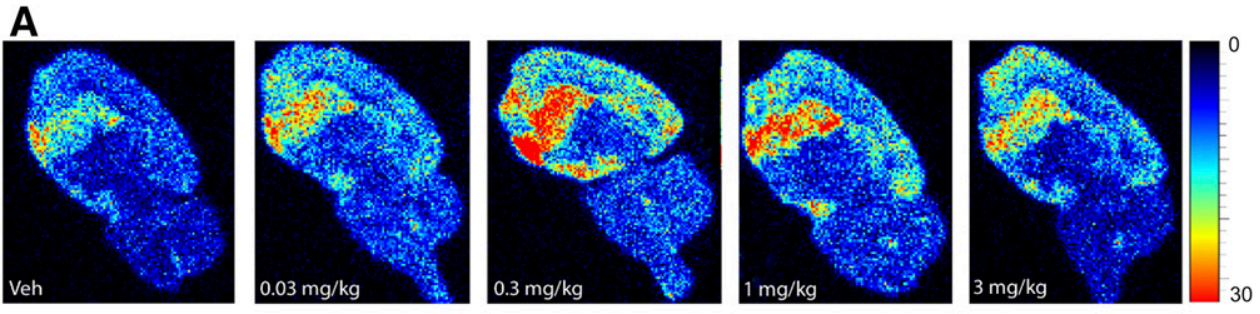

B

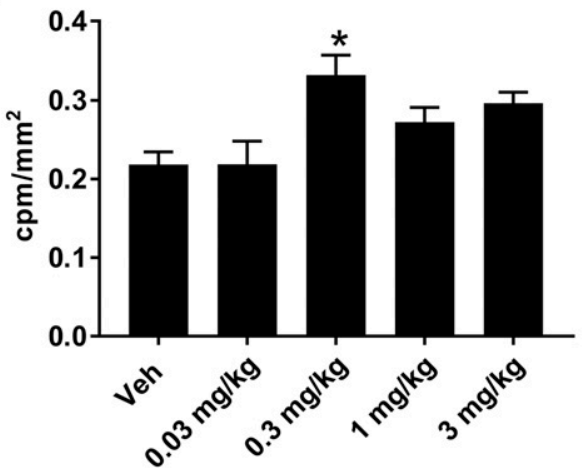

C

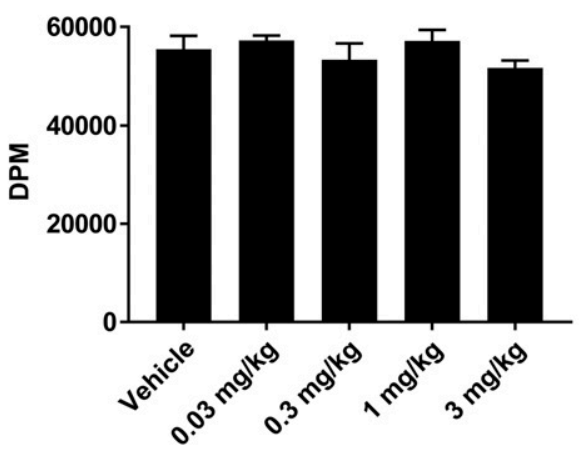

Fig. 4. PDE2A target binding following the lower oral range $(0.03-3 \mathrm{mg} / \mathrm{kg})$ of $\mathrm{PF}$ 05180999 in the rat. (A and B) PF05180999 significantly increased PDE2A tracer binding at the dose of $0.3 \mathrm{mg} / \mathrm{kg}$ and the binding intensity tended to return to baseline when the doses of the drug were increased ( $n=3$ per group). (C) Plasma radioactivity levels remained constant 10 minutes after $0.5 \mu \mathrm{Ci} / \mathrm{g}$ intravenous injection of the tracer right before the brain samples were harvested. cpm, counts per minute; DPM, disintegrations per minute. 


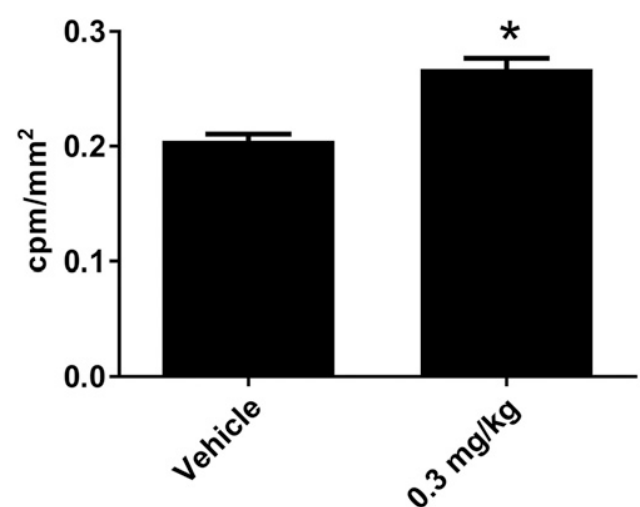

Fig. 5. Comparison of PDE2A tracer binding between vehicle- and PF05180999-treated $(0.3 \mathrm{mg} / \mathrm{kg}$, by mouth, 1 hour postdosing) groups. PF05180999 significantly increases the binding. $n=7$ in the vehicle group and $n=8$ in the drug treatment group. cpm, counts per minute.

change the occupancy-pharmacodynamic relationship as revealed in the present study.

As demonstrated in the present study, the positive cooperativity by increased cGMP is suggested as the reason for the PDE2A inhibitor-induced increase in PDE2A binding site availability. The major substrate of PDE2A cGMP not only binds to the catalytic domain, but also allosterically binds, with higher affinity, to the GAF-B domain (Wu et al., 2004), leading to increased affinity in the PDE2A enzyme through conformational changes of the binding pocket in the catalytic subunit (Martins et al., 1982; Pandit et al., 2009). It is our understanding that, under normal circumstances, only a small portion of the PDE2A pool is activated by endogenous cGMP in the rat brain, and thus only a fraction of the high-affinity binding sites is available to the ligand. Inactivated PDE2A enzymes have very low binding affinity. When the animals are dosed with PDE2A inhibitor, increased levels of cGMP will spill over to the adjacent inactive PDE2A pool, opening the active sites to increase the affinity of those enzymes and causing an increase in the total binding capacity. If, at this time, there is not enough compound nearby (in quantity or potency, or both), an increase in PDE2A binding is observed. This resembles the activation phase that Pandit et al. (2009) had proposed in an experiment investigating ${ }^{3} \mathrm{H}-5^{\prime}$-GMP binding in the presence of ascending concentrations of cold cGMP.

Depending on the potency (the $K_{\mathrm{i}}$ value) of the compound, the activation phase could be narrow or wide. After testing over two dozen orally bioavailable, brain-penetrant PDE2A inhibitors, we found that, except for one compound that has extraordinarily high brain exposure, lower affinity compounds with $K_{\mathrm{i}}$ values higher than $50 \mathrm{nM}$ normally have a wide activation phase, and they cause an increase in PDE2A binding site availability at oral doses of $1-100 \mathrm{mg} / \mathrm{kg}$. The higher dose of the compound is needed to fill in the expanded binding capacity for the demonstration of regular target occupancy. Conversely, higher affinity compounds with $K_{\mathrm{i}}$ values less than $50 \mathrm{nM}$ can yield a regular dose-dependent PDE2A target occupancy profile at the $1-100 \mathrm{mg} / \mathrm{kg}$ dose range, and the negative phase can only be seen in the very low end of the dose range.

The results of our in vitro binding studies in the presence or absence of cGMP support the role of cGMP in the activation of

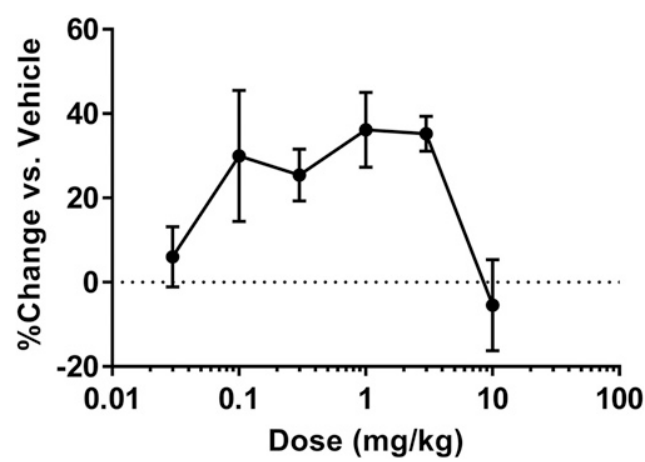

Fig. 6. Increase of PDE2A tracer binding over vehicle treatment after the lower dose range $(0.03-10 \mathrm{mg} / \mathrm{kg})$ of PF-05180999; data combine the results of four separate experiments $(0.03 \mathrm{mg} / \mathrm{kg}, n=6 ; 0.1 \mathrm{mg} / \mathrm{kg}, n=3$; $0.3 \mathrm{mg} / \mathrm{kg}, n=17 ; 1 \mathrm{mg} / \mathrm{kg}, n=9 ; 3 \mathrm{mg} / \mathrm{kg}, n=6$; and $10 \mathrm{mg} / \mathrm{kg}, n=3)$. PF05180999 at the doses of $0.1,0.3,1$, and $3 \mathrm{mg} / \mathrm{kg}$ increases the binding of PDE2A tracer $\left[{ }^{3} \mathrm{H}\right] \mathrm{PF}-05270430$. This increase tends to return to baseline when the dose of the compound is beyond $3 \mathrm{mg} / \mathrm{kg}$.

PDE2A. These results are consistent with previous PDE2A enzymatic velocity studies (Martins et al., 1982; Pandit et al., 2009). Under in vivo conditions, compounds that generate cGMP in the brain via acting on other targets also facilitate PDE2A binding. We (unpublished data) and others (Megens et al., 2017) found that a subcutaneous dose of the PDE10 inhibitor MP-10 could increase in vivo PDE2A binding by 3 - to $\sim 7$-fold. This increase was abolished by pretreatment with NG-Nitro-L-arginine methyl ester, a nonselective nitric oxide synthase inhibitor that blocks the production of cGMP (Megens et al., 2017). In another study (unpublished data), we found that an intraperitoneal dose of ketamine could also significantly increase in vivo PDE2A binding, possibly via a ketamine-induced increase in cGMP in the rat brain (Liebenberg et al., 2015).

The activation of PDE2A following enzyme inhibition appears to be consistent with the roles of PDEs. Under physiologic states, after the system is activated, the increased intracellular cAMP or cGMP is cleaved by PDEs to allow the system to return to the baseline state, and thus get ready for the next round of activation. Higher levels of cyclic nucleotide require higher activity of the enzyme, which could be an increase in the binding affinity of the existing enzymes and/or

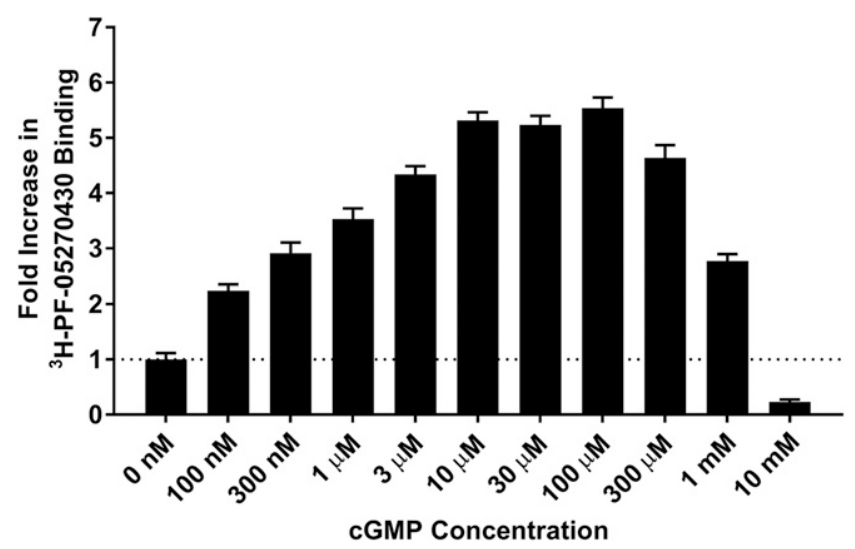

Fig. 7. In vitro PDE2A tracer ${ }^{3} \mathrm{H}-\mathrm{PF}-05270430$ binding with recombinant PDE2A protein (215-900) in the absence or presence of ascending cGMP. PDE2A binding increases with initial ascending concentrations of cGMP, then plateaus, and finally decreases when cGMP concentration becomes higher. 


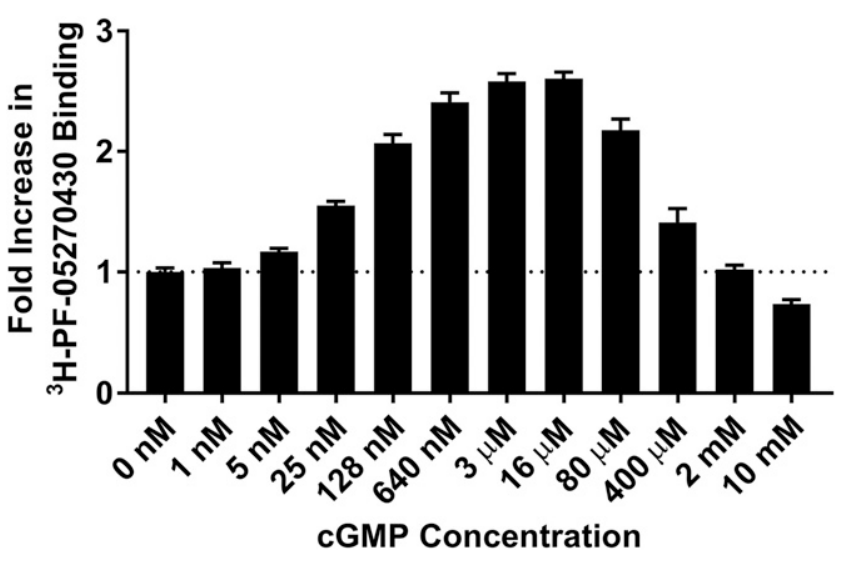

Fig. 8. In vitro PDE2A tracer ${ }^{3} \mathrm{H}-\mathrm{PF}-05270430$ binding with rat brain homogenate that contains native PDE2A protein in the absence or presence of ascending cGMP. Similar to Fig. 6, which uses PDE2A protein (215-900), PDE2A binding increases with initial ascending concentrations of cGMP, then plateaus, and finally decreases when cGMP concentration becomes higher.

an increase in the total activated forms of the enzymes. This activation may not necessarily be a direct effect on the enzyme, such as in PDE2A; it could be an indirect via other intracellular pathways. For example, the activity of PDE1 is dependent on activated $\mathrm{Ca}^{2+}$-calmodulin in the cell (Kakkar et al., 1999). PDE4 inhibition-induced increase of cAMP activates phosphokinase $\mathrm{A}$, which in turn phosphorylates PDE4. Phosphorylated PDE4 has higher enzymatic activity (Itoh et al., 2010; Song et al., 2016). The direct action of cGMP on PDE2A enzyme protein may be associated with faster and more efficient activation, indicative of a frontline status of PDE2A in the PDE family (Polito et al., 2013) in coping with increased cGMP in the brain. The reserve of PDE2A appears to be ample since only about $20 \%$ of the PDE2A is active under physiologic conditions based on the results of in vivo activation with PDE10 inhibitor 2-(4-(1-methyl-4-pyridin-4-yl-1H-pyrazol-3-yl)phenoxymethyl)quinoline (Megens et al., 2017; G. Gu and T. Scott, unpublished data).

It is hard to speculate on the kinetics of PDE2A activation following systemic PDE2A inhibitor administration. One of the important reasons is the lack of information on cGMP produced near the PDE2A enzyme in the subcellular compartments, although global increase of cGMP was detected after

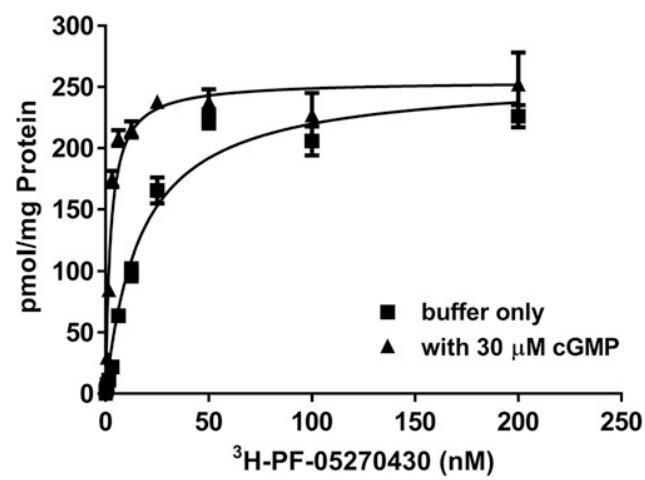

Fig. 9. In vitro PDE2A tracer ${ }^{3} \mathrm{H}-\mathrm{PF}-05270430$ binding with recombinant near-to-full-length PDE2A protein in the absence or presence of $30 \mu \mathrm{M}$ cGMP. The binding saturation curve shifts to the left in the presence of $30 \mu \mathrm{M}$ cGMP compared with the curve treated with buffer alone. Activated PDE2A has over 7-fold higher affinity over the inactive form.
$N$-((1S)-1-(3-fluoro-4-(trifluoromethoxy)phenyl)-2-methoxyethyl)-7methoxy-2-oxo-2,3-dihydropyrido[2,3-b]pyrazine-4(1H)carboxamide or PF-05180999 administration (Mikami et al., 2017a,b; Helal et al., 2018).

Taken together, similar to the in vitro activation and the following inhibition phases in PDE2A binding by ascending concentrations of cGMP (Pandit et al., 2009), the PDE2A inhibitor PF-05180999 also triggers activation and inhibition of PDE2A binding in vivo, although at lower scales. When evaluating target engagement of PDE2A inhibitors for memory disorders in the clinical setting with occupancy assays, the efficacious dose seems unlikely to fall on the typical receptor/ target curve. On the contrary, an increase in the tracer binding could be observed. This increase in PDE2A binding in response to PDE2A inhibitor administration could potentially be used to monitor target engagement in clinical development when no other means is available.

\section{Acknowledgments}

We thank Dr. Teresa Almos for critical comments on this project and Dr. James DeZazzo for reviewing the manuscript.

\section{Authorship Contributions}

Participated in research design: Gu, Scott, Yan, Gomez, Morse, Li, Massari, Breitenbucher, Vivian, Danks.

Conducted experiments: Gu, Scott, Yan, Warren, Zhang.

Contributed new reagents or analytic tools: Xu, Aertgeerts, Gomez, Breitenbucher.

Performed data analysis: Gu, Scott, Yan, Warren, Tabatabaei, Morse, Massari.

Wrote or contributed to the writing of the manuscript: Gu, Scott, Yan, Warren, Massari, Breitenbucher, Danks.

\section{References}

American Psychiatric Association (2013) Neurocognitive disorders, Diagnostic and Statistical Manual of Mental Disorders (DSM-5), 5th ed, American Psychiatric Publishing, Arlington, VA.

Boess FG, Hendrix M, van der Staay FJ, Erb C, Schreiber R, van Staveren W, de Vente J, Prickaerts J, Blokland A, and Koenig G (2004) Inhibition of phosphodiesterase 2 increases neuronal cGMP, synaptic plasticity and memory performance. Neuropharmacology 47:1081-1092.

Brindle PK and Montminy MR (1992) The CREB family of transcription activators. Curr Opin Genet Dev 2:199-204.

Budson AE and Price BH (2005) Memory dysfunction. N Engl J Med 352:692-699. Chen G, Zou X, Watanabe H, van Deursen JM, and Shen J (2010) CREB binding protein is required for both short-term and long-term memory formation. J Neurosci 30:13066-13077.

Chen L, Nabulsi N, Naganawa M, Zasadny K, Skaddan MB, Zhang L, Najafzadeh S, Lin SF, Helal CJ, Boyden TL, et al. (2016) Preclinical evaluation of $18 \mathrm{~F}-\mathrm{PF}$ 05270430, a novel PET radioligand for the phosphodiesterase 2A enzyme. J Nucl Med 57:1448-1453.

Conti M and Beavo J (2007) Biochemistry and physiology of cyclic nucleotide phosphodiesterases: essential components in cyclic nucleotide signaling. Annu Rev Biochem 76:481-511.

Conti M and Richter W (2014) Phosphodiesterases and cyclic nucleotide signaling in the CNS, in Cyclic-Nucleotide Phosphodiesterases in the Central Nervous System (Brandon NJ and West AR eds) pp 1-45, Wiley \& Sons, Hoboken, NJ.

Delnomdedieu M, Forsberg A, Ogden A, Fazio P, Yu CR, Stenkrona P, Duvvuri S, David W, Al-Tawil N, Vitolo OV, et al. (2017) In vivo measurement of PDE10A enzyme occupancy by positron emission tomography (PET) following single oral dose administration of PF-02545920 in healthy male subjects. Neuropharmacology 117:171-181.

Domek-Łopacińska K and Strosznajder JB (2008) The effect of selective inhibition of cyclic GMP hydrolyzing phosphodiesterases 2 and 5 on learning and memory processes and nitric oxide synthase activity in brain during aging. Brain Res 1216:68-77.

Finnema SJ, Halldin C, Bang-Andersen B, Bundgaard C, and Farde L (2015) Serotonin transporter occupancy by escitalopram and citalopram in the non-human primate brain: a $\left[{ }^{11} \mathrm{C}\right]$ MADAM PET study. Psychopharmacology (Berl) 232: $4159-4167$.

Fleischman DA, Wilson RS, Gabrieli JD, Bienias JL, and Bennett DA (2004) A longitudinal study of implicit and explicit memory in old persons. Psychol Aging 19:617-625.

Freedman NM, Mishani E, Krausz Y, Weininger J, Lester H, Blaugrund E, Ehrlich $\mathrm{D}$, and Chisin R (2005) In vivo measurement of brain monoamine oxidase B occupancy by rasagiline, using ${ }^{11} \mathrm{C}-\mathrm{L}$-deprenyl and PET. J Nucl Med 46:1618-1624.

Ginty DD, Kornhauser JM, Thompson MA, Bading H, Mayo KE, Takahashi JS, and Greenberg ME (1993) Regulation of CREB phosphorylation in the suprachiasmatic nucleus by light and a circadian clock. Science 260:238-241. 
Gu G, Rojo AA, Zee MC, Yu J, and Simerly RB (1996) Hormonal regulation of CREB phosphorylation in the anteroventral periventricular nucleus. $J$ Neurosci 16: 3035-3044.

Hargreaves R (2002) Imaging substance P receptors (NK1) in the living human brain using positron emission tomography. J Clin Psychiatry 63 (Suppl 11): $18-24$.

Helal CJ, Arnold E, Boyden T, Chang C, Chappie TA, Fisher E, Hajos M, Harms JF, Hoffman WE, Humphrey JM, et al. (2018) Identification of a potent, highly selective, and brain penetrant phosphodiesterase $2 \mathrm{~A}$ inhibitor clinical candidate. $\mathrm{J} \mathrm{Med}$ Chem 61:1001-1018.

Itoh T, Abe K, Hong J, Inoue O, Pike VW, Innis RB, and Fujita M (2010) Effects of cAMP-dependent protein kinase activator and inhibitor on in vivo rolipram binding to phosphodiesterase 4 in conscious rats. Synapse 64:172-176.

Kakkar R, Raju RV, and Sharma RK (1999) Calmodulin-dependent cyclic nucleotide phosphodiesterase (PDE1). Cell Mol Life Sci 55:1164-1186.

Kandel ER (2012) The molecular biology of memory: cAMP, PKA, CRE, CREB-1, CREB-2, and CPEB. Mol Brain 5:14

Kandel ER, Dudai Y, and Mayford MR (2014) The molecular and systems biology of memory. Cell 157:163-186.

Kapur S, Remington G, Zipursky RB, Wilson AA, and Houle S (1995) The $\mathrm{D}_{2}$ dopamine receptor occupancy of risperidone and its relationship to extrapyramidal symptoms: a PET study. Life Sci 57:PL103-PL107.

Kelly MP, Adamowicz W, Bove S, Hartman AJ, Mariga A, Pathak G, Reinhart V, Romegialli A, and Kleiman RJ (2014) Select 3',5'-cyclic nucleotide phosphodiesterases exhibit altered expression in the aged rodent brain. Cell Signal 26: $383-397$.

Liebenberg N, Joca S, and Wegener G (2015) Nitric oxide involvement in the antidepressant-like effect of ketamine in the Flinders sensitive line rat model of depression. Acta Neuropsychiatr 27:90-96.

Lu Z and Ding L (1999) Blockade of a retinal cGMP-gated channel by polyamines. $J$ Gen Physiol 113:35-43.

Martinez SE, Wu AY, Glavas NA, Tang XB, Turley S, Hol WG, and Beavo JA (2002) The two GAF domains in phosphodiesterase 2A have distinct roles in dimerization and in cGMP binding. Proc Natl Acad Sci USA 99:13260-13265.

Martin-Facklam M, Pizzagalli F, Zhou Y, Ostrowitzki S, Raymont V, Brašić JR Parkar N, Umbricht D, Dannals RF, Goldwater R, et al. (2013) Glycine transporter type 1 occupancy by bitopertin: a positron emission tomography study in healthy volunteers. Neuropsychopharmacology 38:504-512.

Martins TJ, Mumby MC, and Beavo JA (1982) Purification and characterization of a cyclic GMP-stimulated cyclic nucleotide phosphodiesterase from bovine tissues. J Biol Chem 257:1973-1979.

Megens AA, Langlois X, and, and Andres-Gil JI (2017) inventors. Combinations comprising PDE2A inhibitors such as 1-aryl-4-mehyl-1,2,4 triazolo 4,3-aquinoxaline compounds and PDE10 inhibitors for use in the treatment of neurological or metabloic disorders. U.S. patent 9,669,035B2. Assignee: Janssen Pharmaceutica NV, Beerse (BE). Date of Patent: Jun 6, 2017

Mikami S, Kawasaki M, Ikeda S, Negoro N, Nakamura S, Nomura I, Ashizawa T, Kokubo H, Hoffman ID, Zou H, et al. (2017a) Discovery of a novel series of pyrazolo [1,5-a]pyrimidine-based phosphodiesterase $2 \mathrm{~A}$ inhibitors structurally different from $N$-((1S)-1-(3-fluoro-4-(trifluoromethoxy)phenyl)-2-methoxyethyl)-7-methoxy2-oxo-2,3-dihydropyrido[2,3-b]pyrazine-4(1H)-carboxamide (TAK-915), for the treatment of cognitive disorders. Chem Pharm Bull (Tokyo) 65:1058-1077.

Mikami S, Nakamura S, Ashizawa T, Nomura I, Kawasaki M, Sasaki S, Oki H, Kokubo H, Hoffman ID, Zou H, et al. (2017b) Discovery of clinical candidate $N$-((1S)-1-(3-fluoro-4-(trifluoromethoxy)phenyl)-2-methoxyethyl)-7-methoxy-2-oxo-2,3dihydropyrido[2,3-b] pyrazine-4(1H)-carboxamide (TAK-915): a highly potent, selective, and brain-penetrating phosphodiesterase $2 \mathrm{~A}$ inhibitor for the treatment of cognitive disorders. J Med Chem 60:7677-7702.

Montminy MR, Gonzalez GA, and Yamamoto KK (1990) Regulation of cAMP inducible genes by CREB. Trends Neurosci 13:184-188.

Naganawa M, Waterhouse RN, Nabulsi N, Lin SF, Labaree D, Ropchan J, Tarabar S, DeMartinis N, Ogden A, Banerjee A, et al. (2016) First-in-human assessment of the novel PDE2A PET radiotracer 18F-PF-05270430. J Nucl Med 57 1388-1395.
Nakashima M, Imada H, Shiraishi E, Ito Y, Suzuki N, Miyamoto M, Taniguchi T, and Iwashita H (2018) Phosphodiesterase 2A inhibitor TAK-915 ameliorates cognitive impairments and social withdrawal in $N$-methyl-D-aspartate receptor antagonist-induced rat models of schizophrenia. J Pharmacol Exp Ther $\mathbf{3 6 5}$ 179-188.

Pandit J, Forman MD, Fennell KF, Dillman KS, and Menniti FS (2009) Mechanism for the allosteric regulation of phosphodiesterase 2A deduced from the X-ray structure of a near full-length construct. Proc Natl Acad Sci USA 106:18225-18230.

Paul C, Stratil C, Hofmann F, and Kleppisch T (2010) cGMP-dependent protein kinase type I promotes CREB/CRE-mediated gene expression in neurons of the lateral amygdala. Neurosci Lett 473:82-86.

Petersen RC, Smith GE, Waring SC, Ivnik RJ, Tangalos EG, and Kokmen E (1999) Mild cognitive impairment: clinical characterization and outcome. Arch Neurol 56: 303-308.

Polito M, Klarenbeek J, Jalink K, Paupardin-Tritsch D, Vincent P, and Castro LR (2013) The NO/cGMP pathway inhibits transient cAMP signals through the activation of PDE2 in striatal neurons. Front Cell Neurosci 7:211.

Poo MM, Pignatelli M, Ryan TJ, Tonegawa S, Bonhoeffer T, Martin KC, Rudenko A Tsai LH, Tsien RW, Fishell G, et al. (2016) What is memory? The present state of the engram. BMC Biol 14:40.

Raddad E, Chappell A, Meyer J, Wilson A, Ruegg CE, Tauscher J, Statnick MA Barth V, Zhang X, and Verfaille SJ (2016) Occupancy of nociceptin/orphanin FQ peptide receptors by the antagonist LY2940094 in rats and healthy human subjects. Drug Metab Dispos 44:1536-1542.

Schmidt CJ (2010) Phosphodiesterase inhibitors as potential cognition enhancing agents. Curr Top Med Chem 10:222-230.

Silva AJ, Kogan JH, Frankland PW, and Kida S (1998) CREB and memory. Annu Rev Neurosci 21:127-148.

Soderling TR (1999) The $\mathrm{Ca}^{2+}$-calmodulin-dependent protein kinase cascade. Trends Biochem Sci 24:232-236.

Song RS, Tolentino R, Sobie EA, and Neves-Zaph SR (2016) Cross-regulation of phosphodiesterase 1 and phosphodiesterase 2 activities controls dopaminemediated striatal $\alpha$-amino-3-hydroxy-5-methyl-4-isoxazolepropionic acid (AMPA) receptor trafficking. J Biol Chem 291:23257-23267.

Stephenson DT, Coskran TM, Kelly MP, Kleiman RJ, Morton D, O’Neill SM, Schmidt CJ, Weinberg RJ, and Menniti FS (2012) The distribution of phosphodiesterase 2A in the rat brain. Neuroscience 226:145-155.

Stroop SD and Beavo JA (1991) Structure and function studies of the cGMPstimulated phosphodiesterase. J Biol Chem 266:23802-23809.

Teich AF, Nicholls RE, Puzzo D, Fiorito J, Purgatorio R, Fa' M, and Arancio O (2015) Synaptic therapy in Alzheimer's disease: a CREB-centric approach. Neurotherapeutics 12:29-41.

Tully T, Bourtchouladze R, Scott R, and Tallman J (2003) Targeting the CREB pathway for memory enhancers. Nat Rev Drug Discov 2:267-277.

West AE, Chen WG, Dalva MB, Dolmetsch RE, Kornhauser JM, Shaywitz AJ, Takasu MA, Tao X, and Greenberg ME (2001) Calcium regulation of neuronal gene expression. Proc Natl Acad Sci USA 98:11024-11031.

Wu AY, Tang XB, Martinez SE, Ikeda K, and Beavo JA (2004) Molecular determinants for cyclic nucleotide binding to the regulatory domains of phosphodiesterase 2A. J Biol Chem 279:37928-37938.

Yokoi F, Gründer G, Biziere K, Stephane M, Dogan AS, Dannals RF, Ravert H, Suri $\mathrm{A}$, Bramer S, and Wong DF (2002) Dopamine $\mathrm{D}_{2}$ and $\mathrm{D}_{3}$ receptor occupancy in normal humans treated with the antipsychotic drug aripiprazole (OPC 14597): a study using positron emission tomography and $\left[{ }^{11} \mathrm{C}\right]$ raclopride. Neuropsychopharmacology 27:248-259.

Zhang L, et al. (2013) Design and selection parameters to accelerate the discovery of novel central nervous system positron emission tomography (PET) ligands and their application in the development of a novel phosphodiesterase 2A PET ligand. $J$ Med Chem 56 (11):4568-4579, doi: 10.1021/jm400312y.

Address correspondence to: Dr. Guibao Gu, 12278 Scripps Summit Drive, San Diego, CA 92131. E-mail: gug726@yahoo.com 